\title{
Language Attitude of Adolescent Shina Speakers Towards Shina, Urdu and English in Schools of Gilgit-Baltistan, Pakistan
}

\author{
Rumana Nazir ${ }^{1}$, Maisoor Ahmed Nafees ${ }^{2,}$,, Saifuddin $^{2}$, Mahrukh Nafees ${ }^{3}$ \\ ${ }^{1}$ Department of Linguistics and Literature, University of Management and Technology, Lahore, Pakistan \\ ${ }^{2}$ Faculty of Life Sciences, Karakorum International University, Gilgit, Pakistan \\ ${ }^{3}$ Department of Psychology, International Islamic University, Islamabad, Pakistan
}

Email address:

maisoor.nafees@kiu.edu.pk (M. A. Nafees)

${ }^{*}$ Corresponding author

\section{To cite this article:}

Rumana Nazir, Maisoor Ahmed Nafees, Saifuddin, Mahrukh Nafees. Language Attitude of Adolescent Shina Speakers Towards Shina, Urdu and English in Schools of Gilgit-Baltistan, Pakistan. Communication and Linguistics Studies. Vol. 3, No. 3, 2017, pp. $22-27$.

doi: 10.11648/j.cls.20170303.11

Received: December 6, 2017; Accepted: December 25, 2017; Published: February 1, 2018

\begin{abstract}
Gilgit-Baltistan is one of the most culturally, ethnically and linguistically diverse areas of Pakistan. Unfortunately, almost all the languages used in Gilgit-Baltistan exist only in spoken form and lack proper orthography. Furthermore, the lack of patronage from government and educational sectors has directly affected the significance and value of these languages. The only institutionalized languages in this area are Urdu and English like the rest of the country. Keeping in view the present scenario, this study was an attempt to explore the language attitudes of a group of fifty native adolescents of Shina speech community living in Gilgit. Matched guised technique was used to elicit the unconscious responses of the respondents toward the different languages under investigation (English, Urdu and Shina languages). A brief language attitude questionnaire was also used to enhance the authenticity of the research. The collected data was statistically analyzed by using the SPSS software. The result clearly showed that the respondents were instrumentally inclined to learn English and Urdu as these languages offer more privileges and benefits as compared to Shina language. Different reasons related to the low evaluation and ratings of Shina were discussed along with the consequences. It was concluded that the vitality of Shina language may be threaten if such negative attitudes persist. Finally, some recommendations were given to uplift and safeguard the status of Shina language.
\end{abstract}

Keywords: Shina, Gilgit-Baltistan, Urdu, Adolescent

\section{Introduction}

The erstwhile Northern Area of Pakistan, now called Gilgit-Baltistan, is known for its cultural and ethnic diversity throughout the world. This area of Pakistan is equally famous for its rich linguistic setting and multilingual features with more than five languages in use. These languages include Shina, Balti, Brushaski, Wakhi and Khawar. Unfortunately, all the languages exist only in spoken form without any proper orthography. It is also worth mentioning here that Gilgit- Baltistan had been under indirect control of federal government after independence till early 1970s when then Prime Minister Zulfiqar Ali Bhutto first time abolished
Frontier Crimes Regulation Act (FCR) and introduced political reforms. In 2009 Pakistan People's Party (PPP) introduced Empowerment and Self Rule Order 2009, bringing Gilgit-Baltistan's status at par with a province. However Gilgit-Baltistan is an administrative province only and not a constitutional one as are the rest of the four provinces. There is no predefined language policy in this region.

Out of the five languages spoken in Gilgit Baltistan, Shina language has the largest number of speakers, majority of which live in the capital (Gilgit) with additional communities found in Diamar and Baltistan districts. Gilgit city, being the major cultural and economic hub, is the host of people of all the districts of Gilgit Baltistan. A significant number of 
people from different areas of Pakistan also dwell there. In such a multi-lingual society, with no language in common, Urdu is used as a lingua franca for wider communication. Moreover, the influential languages spoken in government, educational and private sectors are Urdu and English.

Despite being spoken by the majority of the people of Gilgit-Baltistan, Shina is still considered a minority language. The reason is that it has never been given the status of provincial language like Sindhi in Sindh. It is not spoken by the majority of people as is the case with Punjabi and Pashto languages in their respective provinces. Unlike, Balochi or any other major language, it does not have any written literature. On top of it, the natives are not aware of their linguistic rights. Even the speakers of Saraiki language in Western Punjab know that as they distinguish themselves on the basis of language from Punjabis [1].

The lack of patronage from government and educational sectors has directly affected the significance and value of Shina language. The promotion of English and Urdu by the electronic and print media has also negatively influenced the worth of this language. Rehman [2] rightly observed that state policy has favoured English and Urdu at the expense of other languages in Pakistan. Media, urbanization and schooling spread Urdu while the other Pakistani languages retreat. In a nutshell, national unity is strengthened as a result of privileging Urdu while, simultaneously and paradoxically, linguistic and cultural diversity in the country is threatened. This is also true in the context of Gilgit Baltistan where plurality of the people use Shina language yet it has never been used in the domains of power and education sectors. Furthermore, Shina has neither been part of school curriculum nor spoken by those at helm of affairs, something which itself is a big threat for its existence. This policy has negative effects on the attitudes of adolescents of Shina language towards the usefulness of their language. The educational policy of "no local language at school" has changed the attitudes of students especially the adolescents towards the usefulness of their native language. The social and electronic media has also affected the language attitude of the masses by promoting only the dominant languages, as majority of the news, entertainment and sports channels are broadcasted in English and Urdu. The adolescents are more influenced by the social and electronic media as compared to the older generation, so they frequently tend to use the prestigious varieties. The status and vitality of a language is often related to the attitudes towards it. So, this research will investigate the social status of Shina language by measuring the attitudes of the native adolescents towards it.

\section{Methodology}

For the present test, an educated local bilingual speaker (female) having sound command on the three languages, was recorded, reading the same passage thrice, once in Urdu and then in English and Shina. The content of the text was chosen on the basis that it would be familiar to the judges so that they would concentrate on the languages rather than on the text. The selected text was a paragraph taken from an essay. The text was then translated into the three given varieties (English, Urdu and Shina) after considerable care and consultation, three additional voices or fillers were also recorded in the given three versions (Shina, Urdu and English). These recordings (distracters) or fillers were played interspersed with the main recordings to avoid listeners being aware of hearing the same speaker thrice. According to Drager [3] fillers are token that are employed to fill in the experiment. Fillers are crucial so that listeners aren't focusing too much on their responses to target token (language). In this test total six recordings were used as experimental stimuli to trigger response in the minds of the respondents according to the personality of the speaker. Experimental stimuli are the triggers in matched guise test that cause (or could cause) a response. In speech perception work, they may be the auditory tokens of sounds, words, or sentences, image or a video.

Table 1. Sequence of the recording providing the stimulus.

\begin{tabular}{lll}
\hline Guise & Recording & Experimental Stimulus \\
\hline \multirow{2}{*}{ EG (English Guise) } & Recording1 & Filler \\
& Recording2 & Target token \\
\multirow{2}{*}{ UG (Urdu Guise) } & Recording3 & Filler \\
& Recording4 & Target token \\
SG (Shina Guise) & Recording5 & Filler \\
& Recording6 & Target token \\
\hline
\end{tabular}

Total six experimental stimuli (recordings) were ordered in such a way that the three versions of the varieties would alternate each other so the token (filler) voice was followed immediately by its matched guise and only the evolutional reaction to the matched voices was analyzed.

Responses to the fillers were not analyzed whereas, responses to target token were analyzed to test the hypothesis under investigation. In order to elicit their unconscious reaction, respondents were not informed that they would listen to the same voice thrice.

Makenzie [4] says, considerable care should be taken on issues of stimulus control, ensuring that prosodic and paralinguistic features of voice such as pitch, speech rate, voice quality and hesitations remain constant. In order to control the paralinguistic cues Audacity (digital audio editor and computer software) was used.

Respondents:

A sample of 50 adolescents was selected by employing purposive sampling from higher secondary level of a private school (Fauji Foundation Model School). The rational for selecting the educational institution is that it provides ideal multilingual settings to explore the attitudes of the young students towards the three languages, i.e., Shina, Urdu and English.

After judges listened to each voice, they were provided a response sheet of semantic differential scale containing 12 bipolar adjectives and they were also asked to provide their name, age and class. Each voice was heard once, and the respondents were given enough time to complete all their ratings for the heard voice before the next one would be 
played to them. The rationale for using semantic differential scales is that they are relatively easy to set up, administer and code. The use of semantic-differential scales is favourably cost-effective as compared to the other scales [5]. The bipolar adjectives used in this research were mainly taken from the English text books for grade 9th and $10^{\text {th }}$. The vocabulary selection was done after the consultation of relevant English teachers of both the classes respectively by keeping in mind the level of the students.

\section{Results}

\subsection{Evaluation of the Speaker: Preliminary Data}

The data collected in matched guise technique was analyzed by using descriptive statistical package (spss, version 20) to evaluate the three guises of the speaker on each of the twelve traits. Total three dependent variables (languages) were there: SG stands for Shina guise, EG represents English guise and UG is the Urdu guise of the speaker. The informants mean rating of SG, EG, and UG on all traits were computed by using of descriptive statistics. The mean evaluations of the three guises given in table. 2 (appendix) showed that the respondents had evaluated the SG negatively as compared to $\mathrm{UG}$ and $\mathrm{EG}$ on the dimension of five given traits namely competence, education, intelligent, ambitious, wealthy, modern. However, SG was rated more positively as compared to UG and EG for the traits honest, friendly, kind and reliable. However, there was not a significant difference found in evaluations of the two traits confident and responsible

\subsection{Evaluation of the Guises of Speaker: All Traits}

A one way analysis of variance (ANOVA) was conducted to compare and contrast the mean evaluations of all the traits of the three guises of the speaker to check whether the respondents held same attitude toward the three different languages. The difference was statistically significant at 0.05 . In table 3 (given in the appendix) the p-value of all the 10 traits (friendly, honest, modern, kind, intelligent, ambitious, reliable, and educated, wealthy, competent) were statistically significant which was less than $0.05(\mathrm{p}<0.05)$. It showed that the difference in the evaluation of all these 10 traits towards EG, UG and SG are significant. So we could interpret from the results that the respondents' attitudes toward the languages were different on all the 10 traits. Conversely, the p-values of other 2 traits, responsible and confident are more than $0.05(p<0.05)$. The attitudes of the respondents towards EG, UG and SG were insignificant only for the two traits (confident and responsible). Hence, we can conclude that the respondents showed relatively similar pattern of attitudes in the evaluation of these 2 traits towards Shina, Urdu and English languages. In a nutshell, the results clearly rejected the null hypothesis that the respondents held same attitude towards Shina, Urdu and English languages. The results also depicted that the three guises were evaluated differently on dimensions of different traits.

\subsection{Evaluations of Speaker on the Basis of Status and Solidarity}

The overall comparison of the mean evaluations showed interestingly multilayer positions of languages on the basis of solidarity and status. The results showed that Shina language was favoured more with the mean of 4.0 as basis of solidarity as compared to Urdu and English languages. Whereas Urdu was ranked on second number with the overall mean evaluation of 3.6 and English was positioned in the last with the mean of 3.2. The attitudes of the respondents confirmed the stereotypes that existed in the society as they ranked English language highest in terms of status. They rated Urdu language more favourably (mean=3.9) as compared to Shina language $($ mean $=3.0)$ in terms of status. The mean showed neutral attitude at 3, negative attitude below 3 and positive attitude respectively when the mean was above 3 . These results also confirmed the previous researches that local variety is favoured more in terms of solidarity and the prestigious varieties were favoured more on the basis of status. These results also unveiled the mindsets of the masses that have been shaped by our so called educational institutions and language policy makers that are under the hold of the powerful elites. 4.7 Analysis of Language.

Table 2. Overall Mean Evaluations for the languages on the basis of Solidarity and Status.

\begin{tabular}{|c|c|c|c|c|}
\hline & & & Solidarity & Status \\
\hline \multirow[b]{2}{*}{. } & \multirow{2}{*}{$\mathrm{N}$} & Valid & 0 & 0 \\
\hline & & Missing & 2 & 2 \\
\hline \multirow{3}{*}{ Shina } & \multirow{2}{*}{$\mathrm{N}$} & Valid & 50 & 50 \\
\hline & & Missing & 0 & 0 \\
\hline & Mean & & 4.0360 & 3.0567 \\
\hline \multirow{3}{*}{ Urdu } & \multirow{2}{*}{$\mathrm{N}$} & Valid & 50 & 50 \\
\hline & & Missing & 0 & 0 \\
\hline & Mean & & 3.6360 & 3.9333 \\
\hline \multirow{3}{*}{ English } & \multirow{2}{*}{$\mathrm{N}$} & Valid & 50 & 50 \\
\hline & & Missing & 0 & 0 \\
\hline & Mean & & 3.2520 & 4.2300 \\
\hline
\end{tabular}

$\mathrm{N}=$ number

\subsection{Attitude Questionnaire}

At the end of the matched guise test the respondents were then asked to fill a short close ended language attitudes questionnaire for comparative purposes.

Q1. Speaking Shina is an advantage.

Q2. I prefer using Shina outside my home.

Q3. I prefer using Shina when talking to my family members.

Q4. English and Urdu offer in seeking good job opportunities.

The result from the data of the questionnaire revealed that according to the $44 \%$ of the respondents speaking Shina was an advantage and about $56 \%$ of the respondents did not agree with the statement that using Shina was an advantage. Only $20 \%$ respondents agreed that they used Shina outside their home while $12 \%$ of the total respondents strongly agreed that they used Shina language outside their homes. However, $44 \%$ disagreed and $24 \%$ strongly disagreed the notion of 
using Shina language outside their home. 32\% were in agreement that they used Shina language with the family members while $68 \%$ of the total respondents strongly agreed that they used Shina language only with their family members.6\% agreed and 94\% strongly agreed that knowledge of English and Urdu language is important for a better job than the knowledge of Shina language. The responses of the language attitude questionnaire clearly showed that the respondents ranked English and Urdu higher than Shina language. The reason is that they were instrumentally motivated towards English and Urdu languages because both these languages offer more benefits as compared to Shina language. There is an element of cultural hegemony attached to these languages as they are used in the sectors of power. The knowledge of English and Urdu is prerequisite for white collar jobs. The hegemony of both these languages has made the local languages suffer throughout Pakistan and they are considered as useless as compared o these prestigious languages. The native speakers especially the younger generation has developed negative attitudes towards Shina language as it offers no opportunities and benefits to its speakers.

Table 3. The Semantic-Differential Scale

\begin{tabular}{lllllll}
\hline Quality & $\mathbf{1}$ & $\mathbf{2}$ & $\mathbf{0}$ & $\mathbf{- 1}$ & $\mathbf{- 2}$ & Quality \\
\hline Honest & 1 & 2 & 0 & -1 & -2 & Dishonest \\
Friendly & 1 & 2 & 0 & -1 & -2 & Unfriendly \\
Modern & 1 & 2 & 0 & -1 & -2 & Old fashioned \\
Responsible & 1 & 2 & 0 & -1 & -2 & Irresponsible \\
Kind & 1 & 2 & 0 & -1 & -2 & Mean \\
Confident & 1 & 2 & 0 & -1 & -2 & Unconfident \\
Intelligent & 1 & 2 & 0 & -1 & -2 & Unintelligent \\
Wealthy & 1 & 2 & 0 & -1 & -2 & Poor \\
Ambitious & 1 & 2 & 0 & -1 & -2 & Lazy \\
Reliable & 1 & 2 & 0 & -1 & -2 & Unreliable \\
Educated & 1 & 2 & 0 & -1 & -2 & Uneducated \\
Competent & 1 & 2 & 0 & -1 & -2 & Incompetent \\
\hline
\end{tabular}

The respondents' responses were tabulated for the individual traits of the twelve bipolar adjectives. The responses were rearranged for the statistical analysis because the positive and negative traits were distributed randomly on semantic differential scale (figure 1). The scale was arranged as 5, 4, 3, 2 and 1 . Where, 5= strongly conform, $4=$ conform, $3=$ neutral, $2=$ disconfirm and $1=$ extremely disconfirm. 5 and 4 represent positive attitudes towards a trait whereas 3 represents neutral position and 2 and 1 depict negative evaluation of a given trait on the scale.

\section{Discussion}

Pakistan has inherited the legacy of language policy from its colonial past. Pakistan represents three categories of people on the basis of language, the first are the elites, the people with high prestige and power who use prestigious language that make them different from the masses. The second category contains the middle class people who are conscious about their choice of language and are always keen to up lift their social status by learning the prestigious languages for their betterment. The last category consists of the marginalized people using indigenous languages. Majority of the people of this class are usually loyal to their language and throughout their lives they struggle to survive. Unfortunately, the state policy of language has always been controlled and dictated by the powerful elites of Pakistan. In the name of globalization, colonization and modernization, they continuously suppress the indigenous linguistics minorities and exploit the assets of the country to maintain their supremacy, ultimately creating a deficit in the distribution of economy and power. They favour the hegemony of English and Urdu over the indigenous languages on purpose as these languages are prestigious and their use make them different from the common masses. Furthermore, the educational system of Pakistan has always been a puppet in hands of these elites and they used it as a tool to sustain the post-colonial language policy that had been made immediately after the emergence of Pakistan in 1947. Both English and Urdu languages are used as means to maintain the class distinction as both these languages are considered symbol of power and prestige. Moreover, these languages have clearly an edge over the other languages as they are used in the sectors of power like private sector, government, corporate sector, education e.tc [6]. This unequal distribution of power and wealth creates unrest in the member of indigenous speech communities as they can't get their due share in the power and economy without learning the dominant languages. The usefulness of their language is jeopardized because of this sort of attitudes. However, still we can't deny the importance of English as it is an international language and its knowledge is obligatory to keep pace with the new developments in science and technology. In fact, it is considered as a gate way to success in Pakistan and its knowledge is a must for white collar jobs, higher education and upward social mobility [7].

Here, in Pakistan people have attached very wrong connotations with the English language like elsewhere in the developing post-colonial countries, like proficiency in English language shows how intellectual, educated and wellmannered you are, while those who don't have command on this language are not even considered worthy of white collar jobs. In nutshell, the lack of proficiency of English language means lack of education, sophistication and manners. On the other hand, Urdu being the national language is considered as a symbol of national integrity. The use of Urdu is preferred as compared to other local and indigenous languages as there is a factor of cultural hegemony attached to it. According to Rehman the powerful section of bureaucracy (the Mohajirs) supported the hegemony of Urdu language which made them more cultured as compared to common man. In fact the real problem arises when these languages are used to marginalize and localize the indigenous languages. For this purpose the private institutions play a very destructive role specially in spreading the phobia (virus) of English language. Even the second rated English medium schools that have been opened in every nook and cranny of the country are far more 
successful in creating the fuss of English language as compared to the standard English medium schools. Though in these schools English language is not taught according to the required standard with trained teachers, yet they seem very successful in imparting the charisma of English language in the minds of the children. As a result, English seems something very attractive, desirable and at the same time unapproachable to these students. In these schools and even in government schools, the students are not allowed to talk in their native language, in other words they are continuously reminded that their language is useless and unworthy. All these things create a void in the minds of the students about the worth of their language. As a result, they seem to develop an indifferent attitude towards their local language.

In European countries when a child of a minor language is told that his language is inferior, it is indirectly implied that the child is inferior. In a nutshell, it means that the language they use is stigma instead of cultural capital [8]. In this scenario the present study is also an attempt to measure the attitude of adolescents of Shina towards Shina language. Backstrom and Radloff [9] had carried out a sociolinguistic survey of the languages of Northern areas of Pakistan. They had investigated the dialects of Shina and the standard dialect and a small portion of attitude was included where the respondents were asked to show their opinion towards literature in Urdu and Shina language. Majority of the respondents considered Urdu language best for literature as compared to Shina language. Likewise, Rehman, conducted a survey of the 59 minor or lesser acknowledged languages of Pakistan that were under tremendous pressure not only from Urdu but also from English. Shina was also included in the list of minor languages where the local activists showed their concern about the influence of English and Urdu on Shina language. The study of language attitude is one of the neglected areas in Pakistan as bulk of previous studies focused on language attitude investigations with relation to the second language learning. However, the investigation of Mansoor [10] is worth-mentioning in this regard. She investigated the language attitudes of Punjabi and Urdu speaking students in the context of English language learning. The result revealed that the university students showed positive attitudes towards English and Urdu, and negative attitudes towards Punjabi language. Likewise, Rehaman's findings also pointed out what he calls the 'culture shame' of educated Punjabis about their language (1999, p.275, 231). The same phenomena was observed by a Punjabi researcher, Lakh Pasha as documented in a research conducted by British council on language of education in Pakistan. He says "It is the birthright of every child to be educated in his mother tongue; our Punjabi child has been deprived of this birthright. He is called derogatory names like being an idiot, illiterate and an ox. He has been made ashamed of his language [11].

The present study is also an attempt in this regard to investigate the language attitude of natives of minority language in a multilingual society. In this regard,
Adolescents' attitudes towards Shina language was investigated in the context of Urdu and English language learning environment. Actually, it was an attempt to evaluate the vitality of the Shina language as attitude plays an important in the vitality and maintenance of minor languages. Minority languages are much more vulnerable to language shift and language loss as compared to majority languages. According to Grenoble and Whaley [12] speech community's attitude towards its own and other language plays a vital role in the prediction of language shift. The result of the present study clearly shows that there is a significant change in the attitudes of speakers of Shina language. The adolescents evaluated the prestigious and dominant languages English and Urdu more positively as compared to Shina language in terms of status. The data collected from the questionnaire clearly depicts that the younger members of Shina speech community have developed somewhat indifferent attitudes towards it. For them the use of Shina offers no benefits.

There are many reasons for this change in attitude. Shina language offers very little socioeconomic benefits to its speakers as compared to the prestigious languages. The white collar jobs in Pakistan are always associated with the English and Urdu languages. In this situation the members of indigenous languages pragmatically and instrumentally acquire the dominant languages for socioeconomic purposes. Despite being the main language of Gilgit-Baltitan, Shina has never been used in the domains of power, i.e., government and private sectors. This lack of patronage from the government has further worsened the value of Shina language. It has never been the part of school curriculum. The language policy of Pakistan is also responsible in this regard as its policies are clearly objectionable and questionable because it always supports

English and Urdu languages and help them to thrive at the expense of indigenous languages of the country. As a result the indigenous languages are the marker of lower class and shame. Moreover, our education system is responsible to promote the mindset that condemn the use of local languages through the educational institutions whether government or private, which continuously remind the students that the use of indigenous or local languages would make them uncivilized and they are only allowed to be uncivilized at their homes. In other words, this brainwashing of the students results in the loss of domain of language use. In short, such type of negative attitude forces the speaker to use their language only at home. Consequently, natives develop negative attitude when no benefits are offered by their language and it becomes a cultural shame to them instead of cultural capital. The use of the dominant languages also offers some social benefits in terms of prestige. The use of these prestigious languages clearly gives you an edge over the local languages in a social gathering. Since dominant languages are regarded as the symbols of upper class, sophistication and power whereas the indigenous languages are markers of lower class, poverty and lack of manner. In short, the use of 
indigenous language like in the present case Shina, is always related to negative connotation attached to the use of these languages in society.

Such type of attitude represents the stereotypes that exist in society and becomes a threat for the vitality and sustenance of the language which ultimately leads to language endangerment and then to language loss. In order to safeguard a language, the community members or the scholars and the activists must realize the importance of their language. They should make sure that every possible step should be taken to save the language from being subjugated to language endangerment and it is not possible without a proper support and patronage from the government.

\section{Conclusion}

The survival, status and future of minority indigenous languages are questionable throughout the world. The speakers of the indigenous minority languages find these languages worthless so they try to shift to the dominant languages in order to acquire socio-economic benefits and upward social mobility. The inquiry of the language attitudes is crucial as they are the best predicator of the health and future of a language. In Pakistan, a plethora of research has been done on the issues of second language learning so we need to change our future direction of research. Future research should focus on the issues of minority and indigenous languages in order to save them from language shift and language loss. Likewise, majority of research work on Shina language has been done from purely syntax and phonological perspectives. However, the present study is purely the first attempt to measure the language attitudes of the natives towards Shina language. Though, it is clear from this research that Shina language has been evaluated negatively, it is too early to say there is language shift. However, in future studies this research may be replicated on a larger number of students from different schools to conform language shift.

\section{References}

[1] Hashmi, R. S., \& Majeed, G. (2014). Saraiki ethnic identity: Genesis of conflict with state. Journal of Political Studies, 21(1).79-101.

[2] Rehman, T. (2003). Language Policy, Multilingualism and Language Vitality in Pakistan. Retrieved from http//www.ol.sil.org/asia/ldc/parallel_papers/tariq-rehman/pdf

[3] Drager. K. (2013). Experimental methods in Sociolinguistics. In Journal Holmes and Kirk (eds). Research methods in Sociolinguistics: A practical guide (58-73), Wiley-Blackwell.

[4] Gardner, R. C \& Lambert, W. E. (1985). Social Psychology and Second Language Learning: The Role of Attitudes and Motivation. London: Edward Arnold Ltd.

[5] Gardner, R. C., \& Lambert, W. (1972). Attitude and Motivation in second language learning. Rowley, MA: Newbery House.

[6] Rehman, T., (2010). Language policy, identity and religion: Aspects of the civilization of the Muslims in Pakistan and north India. Islamabad, Quaid-i-Azam University.

[7] Ghani, M. (2003). The status and position of English language in Pakistan. Journal of sciences And Humanities, 1 (1), 103115 .

[8] Lambert, W. E., Giles, H., Gardner, R. C., \& Fillerbaum, S. (1960). Evaluation reaction to spoken English. Journal of Abnormal Psychology, 60. 44-51.

[9] Backstorm, C. P., \& Radloff, F. C. (2002). Languages of northern areas. Sociolinguistic survey of Northern Pakistan, 2.417 pp. ISBN 969-8023-12-17.

[10] Mansoor, S. (1993). Punjabi, Urdu, English in Pakistan. A Sociolinguistics study. Karachi: Vanguard books of Language Attitudes and Language Use: A Study of New Mexican Adolescents. Retrieved from https://www.researchgate.net/publication/234560925

[11] Coleman, H., \& Capstick, T. (2012). Language in education in Pakistan: Recommendation for policy and practice. Retrieved from http://www.britishcouncil.org.pk Stuttgart: Franz Steiner Verlag.

[12] Grenoble, L. A., \& Whaley, J. L. (Ed.) (1998). Endangered languages: Current issues and future prospects. Cambridge: Cambridge University Press. 